\title{
Research Paper: Experiential Avoidance and Cognitive Emotion Regulation Strategies as the Mediators in the Relationship Between Mindfulness and Social Anxiety Disorder Symptoms
}

Fatemeh Rezaei ${ }^{1}$, Nasrin Alsadat Hosseini Ramaghani ${ }^{{ }^{*}}$ (D)

Article info:

Received: 08 Aug. 2017

Accepted: 25 Dec. 2017
Keywords:

Mindfulness, Emotion, Anxiety, Student

\section{ABSTRACT}

Objective: The current study seeks to investigate the mechanisms through which mindfulness is related to social anxiety symptoms in a clinical sample of adults by examining whether experiential avoidance and specific cognitive emotion regulation strategies (rumination, catastrophizing, and reappraisal) mediate associations between mindfulness and social anxiety symptoms.

Methods: Statistical population of this study contained all the students with social anxiety disorder in Lorestan University in the academic year 2016-2017. With purposive sampling method, 104 students with social anxiety disorder were selected. Subjects were assessed by Social Phobia Inventory, Beck depression inventory II, Cognitive Emotion Regulation Questionnaire, Social Anxiety Acceptance and Action Questionnaire, and Five Facet Mindfulness Questionnaire. Data were analyzed by SPSS and AMOS 22 software using structural equation modeling, and the model fits the clinical sample well.

Results: In the model, the index demonstrated good fit $\left(\mathrm{X}_{24}=36.13, \mathrm{P}=0.053, \mathrm{GFI}=0.92, \mathrm{AGFI}=0.86\right.$, $\mathrm{CFI}=0.97, \mathrm{NFI}=0.92$, TLI $=0.96$, RMSEA $=0.07, \mathrm{CMIN} / \mathrm{df}=1.50$ ), so that mindfulness facets were directly associated with Sognitive Emotion Regulation Strategies (SERD) and experiential avoidance. It was also found that cognitive emotion regulation strategies and experiential avoidance were associated with social anxiety symptoms. Finally, the results indicated that mindfulness had indirect effects on the social anxiety symptoms that were mediated by cognitive emotion regulation strategies and experiential avoidance.

Conclusion: Our findings raise important implications for clinical health psychologists when tailoring mindfulness-based treatments for SAD patients.

\footnotetext{
* Corresponding Author:

Nasrin Alsadat Hosseini Ramaghani, PhD

Address: Department of Psychology, Faculty of Literature and Humanities, Lorestan University, Khorramabad, Iran.

Tel: +98 (910) 7005927

E-mail: nasrin.ramaghani@gmail.com
} 


\section{Introduction}

ocial Anxiety Disorder (SAD) is characterized by a marked and persistent fear of negative evaluation in social situations (American Psychiatric Association, 2013). It is a chronic psychiatric disorder associated with poor educational and occupational achievement, interpersonal impairment, and considerable psychiatric and medical comorbidity (Grant et al., 2005). This chronic disorder is the fourth most common psychiatric disorder with a lifetime prevalence of $10-15 \%$ and a 1 -year prevalence of 5-10\% (Ohayon \& Schatzberg, 2010). SAD is often treated using Cognitive Behavior Therapy (CBT). Although CBT has been broadly indicated as efficacious for treating social anxiety, many people with social anxiety do not sufficiently benefit from this treatment or achieve only minimal improvement (Hofmann \& Bögels, 2006; Taylor, Abramowitz \& McKay, 2012). Thus, clinicians and researchers have started focusing on other methods of treatment, including mindfulness and acceptance-based interventions.

Mindfulness can be described as the awareness that comes from paying attention to events of the present moment life in an intentional and non-judgmental way (Kabat-Zinn, 1994; Orzech, Shapiro, Brown \& McKay, 2009). A growing number of studies have provided evidence for the effectiveness of mindfulness-based interventions, specifically in the context of social anxiety (Bögels, Sijbers \& Voncken 2006; Kocovski, Fleming, Hawley, Ho \& Antony, 2015; Kocovski, Fleming, Hawley, Huta \& Antony, 2013; Kocovski, Fleming \& Rector, 2009; Shikatani, Antony, Kuo \& Cassin, 2014). Although these findings in support of mindfulness-based treatments for social anxiety are hopeful, further investigations of such interventions are necessary to build support for their use and also to address the mechanism of these treatments. Careful investigation of the hypothesized mechanisms of mindfulness and how these might result in beneficial changes could notify the development and refinement of future treatments.

Emotion regulation is one pathway through which mindfulness demotes psychological distress (anxiety, depression, and stress). Garland, Gaylord and Park (2009) have offered the mindful coping model on the mechanisms of mindfulness on health-related outcomes. According to this model, the positive effect of mindfulness might occur through the process of reappraisal, which acts as an adaptive strategy. Reappraisal involves redefining an emotion-eliciting experience or stimulus (usually negative) in a mode that modifies the effect of that experience (Garland, Gaylord \& Fredrickson, 2011). Emerging evidence reveals that individuals with SAD are less able to apply reappraisal and have lower selfefficacy regarding the use of reappraisal and may engage in more unproductive efforts at reappraisal (Brozovich et al., 2015; Werner, Goldin, Ball, Heimberg \& Gross, 2011; Goldin et al., 2012). Mindfulness practice is associated with increases in positive reappraisal; by mediating reductions in stress through mindfulness practice, individuals may create a broadened state of awareness that facilitates empowering interpretations of stressful life events, leading to strikingly reduced distress (Garland et al., 2011).

Other cognitive emotion regulation strategies that might underlie the processes through which mindfulness decreases symptoms are rumination and reduced catastrophizing (Garland et al., 2011; Desrosiers, Vine, Klemanski \& Nolen-Hoeksema, 2013). Rumination is described by repetitive thoughts about a negative emotional experience, including causal factors and probable consequences of the experience (Nolen-Hoeksema, 1991), and catastrophizing is characterized by the tendency to interpret the events' special ambiguous conditions in a very negative way (Stopa \& Clark, 2000). Individuals with SAD engage in a post-event process that attends to rumination and focus on negative information about themselves and others' opinions of them during the social situation and compare this to an ideal standard (Brozovich et al., 2015; Brozovich \& Heimberg, 2011). Also, individuals with SAD have a tendency to interpret negative social events in a catastrophic fashion (e.g. Vassilopoulos \& Banerjee, 2008; Kingsbury \& Coplan, 2016). Higher levels of rumination and catastrophizing have been frequently associated with lower levels of trait mindfulness (Petrocchi \& Ottaviani, 2015; Garland et al. 2011; Trompetter, Bohlmeijer, Fox \& Schreurs, 2015). Emphasis on the present moment and the nonjudgmental aspect of mindfulness may diminish the abstract self-evaluative thoughts, thereby reducing depression and anxiety (Nolen-Hoeksema, Wisco \& Lyubomirsky, 2008).

Another hypothesized mechanism of mindfulness that demotes psychological distress (anxiety, depression, and stress) is reductions in experiential avoidance (Eustis, Hayes-Skelton, Roemer, \& Orsillo, 2016; Shapiro, Carlson, Astin, \& Freedman, 2006). Previous studies show that adults with $\mathrm{SAD}$, in comparison with a healthy group, reported more experiential avoidance even after controlling for the presence of other comorbid anxiety disorders and depression (Kashdan et al., 2013; Epkins, 2016). Experiential avoidance can be described as a pro- 
cess that occurs when people are unwilling to stay in contact with unpleasant inner experience (Cunha, Galhardo \& Pinto-Gouveia, 2016). The mindfulness practice increases the capacity for objectivity in the relationship to one's internal/external experience and facilitates the acceptance of internal experiences (Shapiro et al., 2006).

Despite initial support for the mediated role of experiential avoidance and cognitive emotion regulation strategies in the relationship between mindfulness and psychological problems, existing studies that have tested these hypotheses have less focused on SAD. However, most studies have used general self-report measures of experiential avoidance (Acceptance and Action Questionnaire), but several complaint-specific measures have been adapted from this scale. Context-specific indices of experiential avoidance have arisen from the belief that general measures of experiential avoidance may possess less utility than those that pertain to certain circumstances. Theoretically, individuals may find it difficult to report avoiding decontextualized thoughts and feelings, as listed in these general measures, and may find it easier to respond by avoiding specific internal events that are associated with particular settings (Sandoz, Wilson, Merwin \& Kellum, 2013; MacKenzie \& Kocovski, 2010). Therefore, in this study, context-specific indices of experiential avoidance have been used (Social Anxiety - Acceptance and Action Questionnaire, MacKenzie \& Kocovski, 2010) that are more sensitive and more precise than the existing Acceptance and Action Questionnaire (Kocovski et al., 2015). Also, according to the data of the researchers of the present study, most former studies of mindfulness and emotion regulation have used non-clinical samples (Desrosiers et al., 2013). In the current study, we synthesize our predictions in the moderated mechanisms of mindfulness for clinical sample of social anxiety according to the previous studies in literature (e.g. Desrosiers et al., 2013; Desrosiers, Vine, Curtiss, Klemanski, 2014; Brown, Bravo, Roos \& Pearson, 2015; Shapiro et al., 2006; Eustis et al., 2016) and the model suggested by Garland et al. (2011)), depicted conceptually in Figure 1. In the current study, this conceptual model is designed to examine whether experimental avoidance and maladaptive cognitive emotion regulation strategies (rumination and catastrophizing) and adaptive cognitive emotion regulation strategies (reappraisal) mediate associations between mindfulness and social anxiety symptoms.

\section{Methods}

A cross-sectional study was used to investigate the direct and indirect associations between facets of mindfulness, rumination, catastrophizing, reappraisal and experiential avoidance in SAD patients. The protocol of the study was approved by the "Regional Ethics Committee" at (the institute where the research was conducted).

Statistical population of this study contained all the students with SAD in Lorestan University in the academic year 2016-2017. The sample consisted of 104 students with SAD, which is in line with the recommendations by Kline (2011), who suggested a sample size of 100

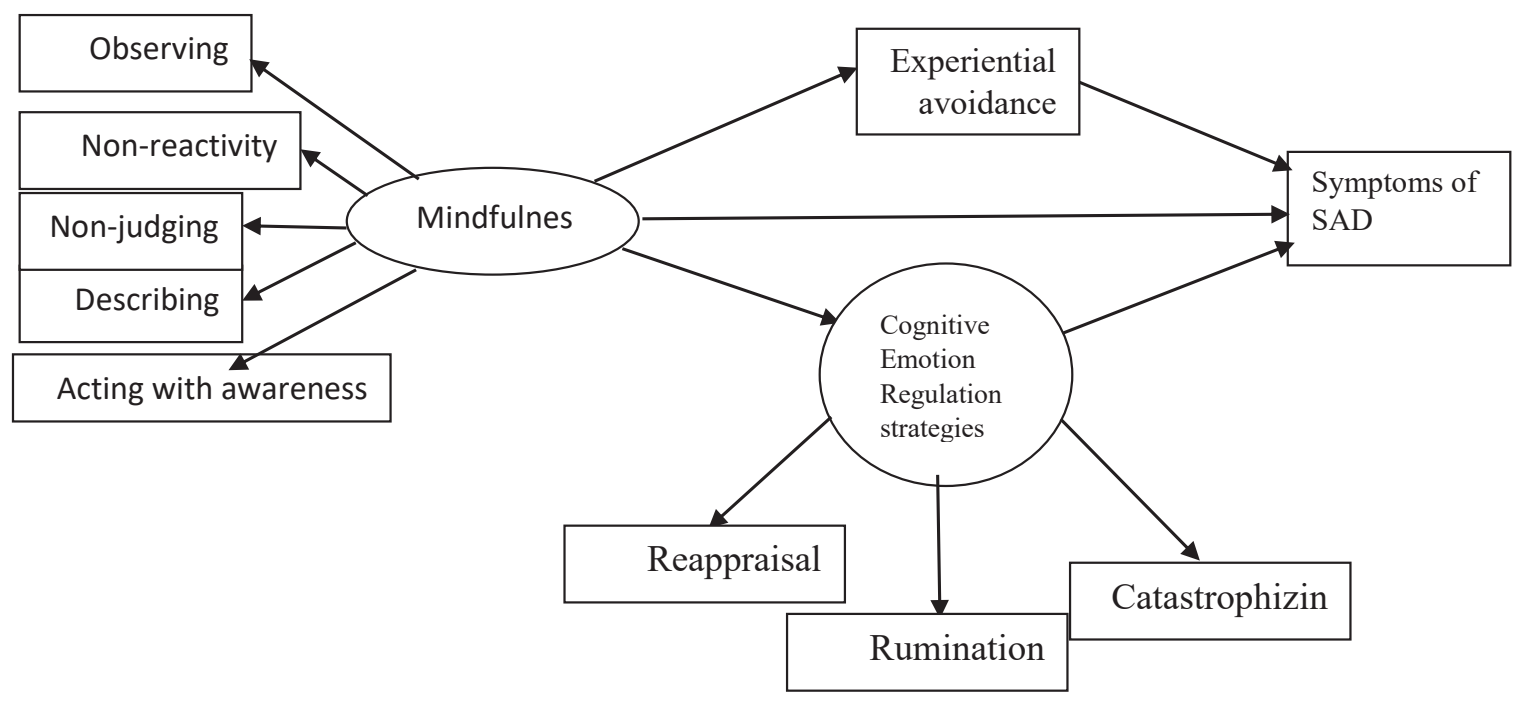

Figure 1. Conceptual diagram of mediation model of SAD symptoms 
to 200 participants when analyzing data using structural equation modeling.

Using purposive sampling method, a sample of 114 socially anxious students were selected based on the following conditions: obtained a score higher than the cutoff point (i.e. 29 points) in the Social Phobia Inventory (SPIN) (Dogaheh, 2013); and received diagnoses of SAD according to the Diagnostic and Statistical Manual for Mental Disorders, fifth edition (DSM-V; APA, 2013) criteria in a clinical diagnostic interview by a doctorate in Clinical Psychology. Of the initial sample of 114 patients, $10(8.77 \%)$ were excluded because of incomplete data. The final sample consisted of 104 patients, including 74 females $(71.2 \%)$ with an age range of 18 to 47 years $(\mathrm{M}=33.91, \mathrm{SD}=7.90)$ and 30 males $(28.8 \%)$ with an age range of 19 to 51 years $(\mathrm{M}=35.8, \mathrm{SD}=8.32)$. There was no significant difference between genders in age.

Inclusion criteria to participate in the current study included: a) receiving diagnosis of SAD by clinicians and b) willingness to participate in the study. Patients were excluded from the study if they: a) had a co-morbid psychiatric disorder except for mild depression (Getting a score below 18 in BDI-II) in a clinical diagnostic interview according to DSM-5, b) were using drugs, c) were participating in psychotherapy, and d) were not willing to participate in study.

Those patients who satisfied the inclusion criteria were then explained the aim and the process of the study, including the ethical considerations such as confidentiality and ability to withdraw without consequence. The patients were then given a questionnaire package and instructions on how to return the completed questionnaires. Data were analyzed using AMOS (Version 22).

The questionnaire package given to the patients consisted of six questionnaires, as outlined below: The Social Phobia Inventory (SPIN), Beck depression inventory II (BDI-II), Cognitive Emotion Regulation Questionnaire (CERQ), Social - Anxiety Acceptance and Action Questionnaire (SA-AAQ), and Five Facet Mindfulness Questionnaire (FFMQ).

Social Phobia Inventory (SPIN) was developed by Connor et al. (2000) to assess social anxiety. It is a 17-item self-report measure of avoidance and fear of a range of social situations and physiological symptoms of anxiety. The SPIN has been validated for use in clinical populations, has discriminant validity and strong convergent, and good internal consistency and test-retest reliability (Radomsky et al., 2006). The psychometric properties of this questionnaire in Iran have also been examined. The reliability of the retest of this test was 0.82 , and its internal consistency was reported by Cronbach's alpha 0.86 (Zanjani, 2010).

Beck depression inventory II (BDI-II) (Beck, Steer, \& Brown, 1996) is a multiple-choice self-report instrument designed to measure both the presence and severity of depressive symptoms. BDI-II contains 21 items, and its answers are scored from 0 to 3 . Higher total scores suggest more severe depressive symptoms. The standardized cutoffs are (different from the original version) as follows: 0-13; minimal depression, 14-19; mild depression, 2028; moderate depression; and 29-63, severe depression (Beck et al., 1996). The BDI-II has been shown to have excellent internal consistency $(\alpha=0.90)$ and good psychometric properties (Storch, Roberti, \& Roth, 2004). The psychometric properties of this questionnaire in Iran have also been examined. Fata, Birashk, Atefvahid and Dabson (2005) reported internal consistency to be 0.91 ., test-retest coefficient to be 0.81 within one week, and correlation coefficient with Beck Anxiety Inventory to be 0.61 .

Cognitive Emotion Regulation Questionnaire (CERQ) (Garnefski, Kraaij \& Spinhoven, 2001) consists of 36 Likert-scaled items and 9 subscales that assess how often certain cogni-tive strategies are used to cope with stressful life events. In this study, reappraisal, rumination and catastrophizing subscales were used. Cronbach's alpha coefficients for these sub-scales are 0.85, 0.81 and 0.70, respectively. The CERQ has been shown to have good internal consistency and convergent validity with subscales of the SCL-90 (Garnefski, Kraaij \& Spinhoven, 2001). The psychometric properties of this questionnaire in Iran have also been examined. Good divergent and convergent validity and internal consistency 0.78- 0.93 has been report-ed (Besharat \& Bazzazian, 2014).

The Social - Anxiety Acceptance and Action Questionnaire (SA-AAQ) developed by MacKenzie \& Kocovski, (2010) was used to assess acceptance or experiential avoidance specific to social anxiety. It was based on the AAQ (Hayes et al., 2004), but so many adapted items reveal a social anxiety context. There was support for a one-dimensional factor structure in two nonclinical samples (MacKenzie \& Kocovski, 2010). Higher scores on the scale represent less experiential avoidance and more acceptance. The SA-AAQ has excellent internal consistency (0.94 in MacKenzie \& Kocovski, 2010). In the present study, psychometric properties of this questionnaire in Iran have been examined. The reliability of 0.89 was obtained using the internal consistency, indicating good convergent validity for this questionnaire. 
Five Facet Mindfulness Questionnaire (FFMQ) was developed by Baer, Smith, Hopkins, Krietemeyer, and Toney (2006) and is a 39-item questionnaire assessing mindfulness in daily life. Researchers mixed items from five existing mindfulness questionnaires into a single data set and performed an exploratory factor analysis. Based on this analysis, researchers found five component skills that contribute to mindfulness: observing (8 items), nonreactivity to inner experiences ( 7 items), not judging of inner experiences ( 8 items), acting with awareness (8 items), and describing ( 8 items) (Baer et al., 2006). Items were rated on a 5-point Likert-type scale. The five-facet scale demonstrated adequate-to-good internal consistency in non-meditators, with $\alpha$ coefficients ranging from 0.75 to 0.91 (Baer et. al 2006). The five factor model is a good fit with experienced meditators (Baer et al., 2008). The psychometric features of the Persian version of this questionnaire have been studied by Dehghani, Esmaeilian, Akbari, Hassanvand (2014) in Iran, whose results indicate favorable internal consistency (0.81-0.93). The convergence and differential validity is appropriate for this scale.

We computed the Pearson correlations between the predictors and outcome variables in SPSS 20.0. Due to the latent variables (e.g. mindfulness and cognitive emotion regulation strategies), the authors tested mediational hypotheses by employing nested Structural Equation Models (SEM) in AMOS 22.0. SEM permits the inclusion of correlated variables and can be used when vari- ables predict other variables (Byrne, 2001). Goodness of fit was assessed by the CMIN/DF (values of 3.0 or less show that the model adequately fits the data), $\mathrm{X}^{2}$ (nonsignificant values $\mathrm{P}>0.05$ indicate that the model adequately fits the data), Goodness of Fit Index (GFI) (values of 0.95 or greater indicate that the model adequately fits the data), Comparative Fit Index (CFI) (values $\geq 0.95$ signify the model fitness), Bentler-Bonett Normed Fit Index (NFI) (values $\geq 0.95$ denote the model fitness to the data), Tucker-Lewis Index (TLI) (values $\geq 0.95$ indicate that the model sufficiently fits the data), and the Root Mean Squared Error of Approximation (RMSEA) (values $\leq 0.08$ suggest that the model adequately fits the data) (Kline, 2011; Browne \& Cudeck, 1993).

An initial model is indicated in Figure 1 SEM required the selection of beginning and endpoints in the cyclical model, and the symptoms of SAD were designed as the endpoint for the model. As shown in Figure 1, the latent construct mindfulness was specified by five facets: observing, non-reactivity to inner experiences, non-judging of inner experiences, acting with awareness and describing. The latent construct Cognitive Emotion Regulation strategies were specified by three strategies: reappraisal, rumination and catastrophizing. Amos software path analysis was conducted to test the model which showed the direct and indirect effects of mindfulness on symptoms of SAD with the mediation of experiential avoidance and Cognitive Emotion Regulation strategies.

Table 1. Descriptive statistics and correlation among mindfulness, experiential avoidance, cognitive emotion regulation strategies and SAD

\begin{tabular}{|c|c|c|c|c|c|c|c|c|c|}
\hline Variables & 1 & 2 & 3 & 4 & 5 & 6 & 7 & 8 & 9 \\
\hline Describe & - & & & & & & & & \\
\hline Acte-aware & $0.23 *$ & & & & & & & & \\
\hline Non-judge & $0.28^{* *}$ & $0.30^{* *}$ & & & & & & & \\
\hline Non-react & $0.26^{* *}$ & $0.27^{* *}$ & $0.27 * *$ & & & & & & \\
\hline $\begin{array}{l}\text { Experiential avoid- } \\
\text { ance }\end{array}$ & $0.27^{* *}$ & $0.34^{* *}$ & $0.24^{*}$ & $0.37^{*}$ & & & & & \\
\hline Reappraisal & $0.27^{* *}$ & $0.28^{* *}$ & $0.30 * *$ & $0.33^{* *}$ & $0.48^{* *}$ & & & & \\
\hline Rumination & $-0.38 * *$ & $-0.30^{* *}$ & $-0.31 * *$ & $-0.35^{* *}$ & $-0.34 * *$ & $-0.67 * *$ & & & \\
\hline Catastrophizing & $-0.39 * *$ & $-0.24^{*}$ & $-0.34^{* *}$ & $-0.37 * *$ & $-0.31 * *$ & $-0.68 * *$ & $0.84^{* *}$ & & \\
\hline SAD & $-0.47^{* *}$ & $-0.42^{* *}$ & $-0.36^{* *}$ & $-0.48 * *$ & $-0.70^{* *}$ & $-0.76^{* *}$ & $0.70^{* *}$ & $0.69^{* *}$ & \\
\hline Mean & 13.77 & 16.39 & 16.56 & 12.76 & 48.74 & 10.25 & 14.52 & 14.90 & 54.06 \\
\hline SD & 4.40 & 4.95 & 4.67 & 4.66 & 22.76 & 4.21 & 4.06 & 4.54 & 12.94 \\
\hline
\end{tabular}




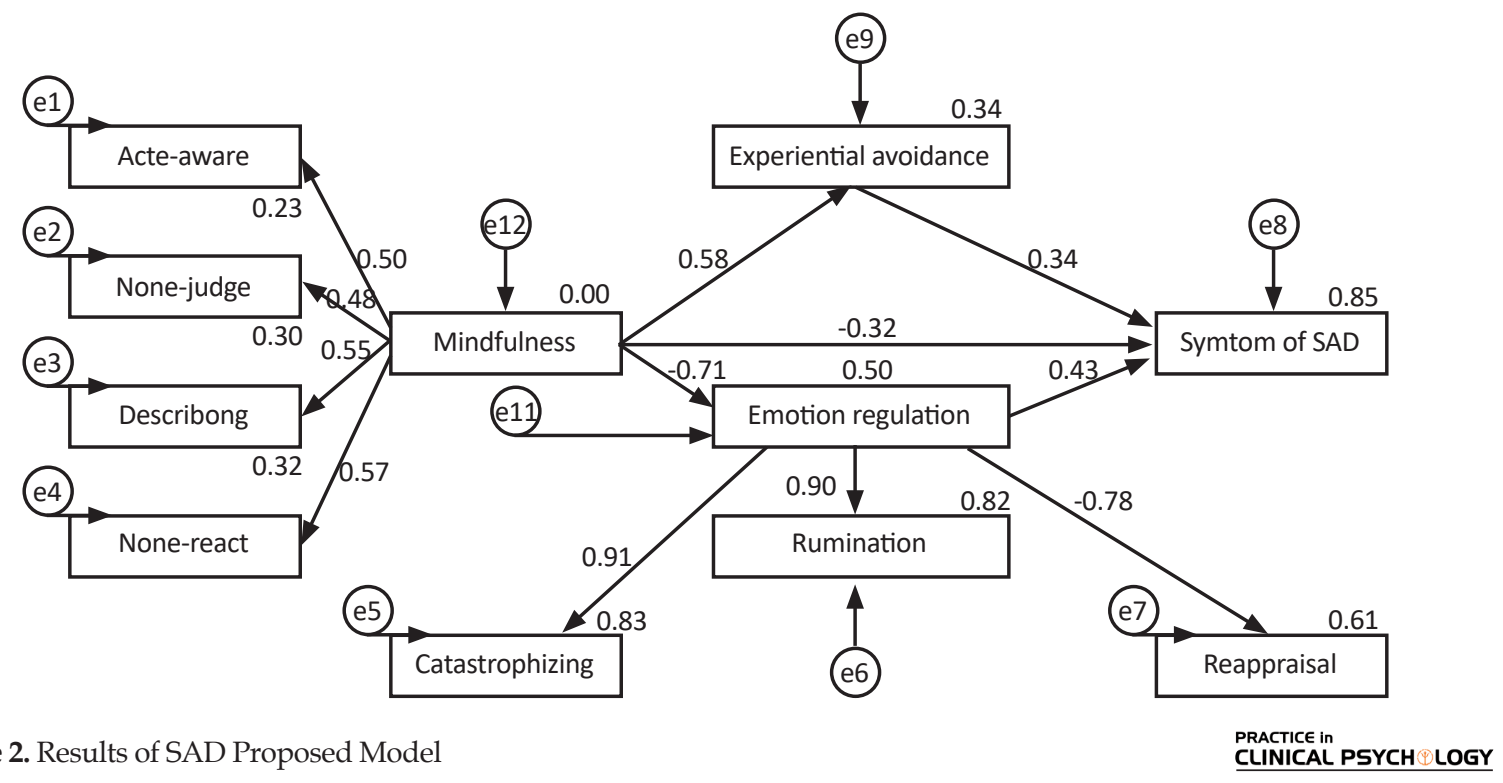

Figure 2. Results of SAD Proposed Model

\section{Discussion}

This study investigated the associated mechanisms between mindfulness and mental health and suggests that the experimental avoidance and certain emotion regulation strategies significantly mediate the relationship between mindfulness and symptoms of social anxiety in adults.

As hypothesized, rumination and catastrophizing (maladaptive cognitive emotion regulation strategies) significantly mediated associations between mindfulness and symptoms of social anxiety. This finding is in line with previous studies in literature (e.g. Desrosiers et al., 2013; Desrosiers et al., 2014; Brown et al., 2015). Theorists have argued that individuals with SAD engage in a post-event process that attends to rumination and focus on negative information about themselves and others' opinions of them during the social situation and compare this to an idealistically standard (Brozovich et al., 2015; Brozovich \& Heimberg, 2011). Also, individuals with SAD have a tendency to interpret mildly negative social events in a catastrophic, fashion way (e.g. Vassilopoulos \& Banerjee, 2008; Kingsbury \& Coplan, 2016). Emphasis on the present moment and the nonjudgmental aspect of mindfulness may diminish the abstract self-evaluative thoughts characteristic of rumination and catastrophizing, thereby, reducing symptoms of social anxiety (NolenHoeksema et al., 2008). The nonjudgmental facet is particularly incompatible with self-critical questioning and may help ruminators disconnect from it, thus decreasing the effects of rumination and maintenance of social anxiety symptoms. 
Our hypothesis for reappraisal was supported in that it significantly mediated the associations between mindfulness and symptoms of social anxiety. This finding is consistent with the neuroimaging studies showing positive correlations between dispositional mindfulness and areas of the brain activated through reappraisal (Modinos, Ormel \& Aleman, 2010) and is consistent with the mindful coping model (Garland et al., 2011) that suggests an increase in dispositional mindfulness and a reduction in stress partly through promoting positive reappraisal. Individuals may develop a broader state of awareness that promotes interpretations of stressful life events, leading to noticeably lower distress (Garland et al. 2011). Also, taking a nonjudgmental style toward experience is in itself a form of redefining that may assist a more general tendency toward the reappraisal of preliminary negative cognitions. This nonjudgmental reappraisal, non-evaluative, or redefining may then lead to improvements in anxiety symptoms (Carmody, 2009; Chambers, Gullone, \& Allen, 2009).

The result of this study for the mediating role of experiential avoidance indicated that it significantly mediated associations between mindfulness and symptoms of social anxiety. This finding is in line with studies that show that anxiety disorders are both characterized and maintained by experiential avoidance (Panayiotou, Karekla \& Panayiotou, 2104; Epkins, 2016) and is consistent with study results that mindful awareness may result in lower experiential avoidance (Weinrib, 2011). Thus, increased mindfulness is related with decreased experiential avoidance, which, in turn, is associated with lower social anxiety symptoms.

Some limitations of the present study need to be highlighted. First, the findings are cross-sectional and correlational, and no causal or temporal relations can be demonstrated. Additionally, sample characteristics are also a limitation, as the focus was on a community sample of treatment-seeking; thus, the generalizability of our results may be limited. Finally, as our study overlooked the mechanisms of action following mindfulness-training, the implications for mindfulness-based interventions are limited. Future studies should examine if self-reported mindfulness following mindfulness-training acts through similar mechanisms, and compare the results on the sample of treatment-seeking and nonclinical samples. Also, it is suggested that future research be conducted on the trans-diagnostic role of the mechanisms of action underlying mindfulness in mood and anxiety disorders.

The current results add to our understanding of the process underlying the relationship between the mindfulness and social anxiety symptoms by revealing that experimental avoidance, maladaptive cognitive emotion regulation strategies (rumination and catastrophizing), and adaptive cognitive emotion regulation strategies (reappraisal) mediate associations between mindfulness and social anxiety symptoms. So it may need to become part of how anxiety disorders (particularly SAD) are conceptualized and treated and protocols for SAD specifically target the experimental avoidance, rumination, catastrophizing and reappraisal.

\section{Acknowledgments}

This research had no financial supporters.

\section{Conflict of Interest}

The authors declared no conflicts of interest.

\section{References}

American Psychiatric Association. (2013). Diagnostic and statistical manual of mental disorders. Washington, D.C.: American Psychiatric Association

Baer, R. A., Smith, G. T., Hopkins, J., Krietemeyer, J., \& Toney, L. (2006). Using self-report assessment methods to explore facets of mindfulness. Assessment, 13(1), 27-45. doi: $10.1177 / 1073191105283504$

Baer, R. A., Smith, G. T., Lykins, E., Button, D., Krietemeyer, J., Sauer, S., et al. (2008). Construct validity of the five facet mindfulness questionnaire in meditating and nonmeditating samples. Assessment, 15(3), 329-42. doi: 10.1177/1073191107313003.

Beck, A. T., Steer, R. A., \& Brown, G. K. (1996). Manual for the Beck Depression Inventory-II. Dallas, TX: The Psychological Corporation.

Besharat, M., A., \& Bazzazian, S. (2014). Psychometric properties of the Cognitive Emotion Regulation Questionnaire in a sample of Iranian population. Advances in Nursing \& Midwifery. 24(84), $61-70$

Bögels, S. M., Sijbers, G. F. V. M., \& Voncken, M. (2006). Mindfulness and task concentration training for social phobia: A pilot study. Journal of Cognitive Psychotherapy, 20(1), 33-44. doi: 10.1891/jcop.20.1.33

Brown, D. B., Bravo, A. J., Roos, C. R., \& Pearson, M. R. (2015). Five facets of mindfulness and psychological health: Evaluating a psychological model of the mechanisms of mindfulness. Mindfulness, 6(5), 1021-32. doi: 10.1007/s12671-014-0349-4.

Browne, M. W., \& Cudeck, R. (1993).Alternative ways of assessing model fit. In K. A. Bollen \& J. SLong (Eds.), Testing Structural Equations Models (pp. 136-62). Newbury Park, CA: SAGA.

Brozovich, F. A., Goldin, P., Lee, I., Jazaieri, H., Heimberg, R. G., \& Gross, J. J. (2015). The effect of rumination and reappraisal on social anxiety symptoms during cognitive- behavioral therapy for 
social anxiety disorder. Journal of Clinical Psychology, 71(3), 208-18 doi: $10.1002 /$ jclp.22132.

Brozovich, F., \& Heimberg, R. G. (2011). The relationship of postevent processing to self-evaluation of performance in social anxiety. Behavior Therapy, 42(2), 224-35. doi:10.1016/j.beth.2010.08.005

Byrne, B. M. (2001). Structural equation modeling with AMOS, EQS, and LISREL: Comparative approaches to testing for the factorial validity of a measuring instrument. International Journal of Testing, 1(1), 55-86. doi: 10.1207/S15327574IJT0101_4

Carmody, J. (2009). Evolving conceptions of mindfulness in clinical settings. Journal of Cognitive Psychotherapy, 23(3), 270-80. doi: 10.1891/0889-8391.23.3.270

Chambers, R., Gullone, E., \& Allen, N. B. (2009). Mindful emotion regulation: An integrative review. Clinical Psychology Review, 29(6), 560-72. doi: 10.1016/j.cpr.2009.06.005.

Connor, K. M., Davidson, J. R., Churchill, L. E., Sherwood, A., Weisler, R. H., \& FOA, E. (2000). Psychometric properties of the social phobia inventory (SPIN). The British Journal of Psychiatry, 176(4), 379-86. doi: 10.1192/bjp.176.4.379.

Cunha, M., Galhardo, A., \& Pinto-Gouveia, J. (2016). Experiential avoidance, self-compassion, self-judgment and coping styles in infertility. Sexual \& Reproductive Healthcare, 10, 41-7. doi: 10.1016/j.srhc.2016.04.001

Dehghani, M., Esmaeilian, N., Akbari, F., \& Hassanvand, M. (2014). Evaluating the psychometric properties and factorial structure of the five dimensional mindfulness questionnaire. Thought $\mathcal{E} \mathrm{Be}$ havior in Clinical Psychology. 9(33), 77-86.

Desrosiers, A., Vine, V., Curtiss, J., \& Klemanski, D. H. (2014). Observing nonreactively: A conditional process model linking mindfulness facets, cognitive emotion regulation strategies, and depression and anxiety symptoms. Journal of Affective Disorders, 165, 31-7. doi: 10.1016/j.jad.2014.04.024.

Desrosiers, A., Vine, V., Klemanski, D. H., \& Nolen-Hoeksema, S (2013). Mindfulness and emotion regulation in depression and anxiety: Common and distinct mechanisms of action. Depression and Anxiety, 30(7), 654-61. doi: 10.1002/da.22124.

Dogaheh, E. R. (2013). Psychometric properties of Farsi version of the Social Phobia Inventory (SPIN). Procedia-Social and Behavioral Sciences, 84, 763-8. doi: 10.1016/j.sbspro.2013.06.642

Epkins, C. C. (2016). Experiential avoidance and anxiety sensitivity: independent and specific associations with children's depression, anxiety, and social anxiety symptoms. Journal of Psychopathology and Behavioral Assessment, 38(1), 124-35. doi: 10.1007/ s10862-015-9502-1.

Eustis, E. H., Hayes-Skelton, S. A., Roemer, L., \& Orsillo, S. M. (2016). Reductions in experiential avoidance as a mediator of change in symptom outcome and quality of life in acceptancebased behavior therapy and applied relaxation for generalized anxiety disorder. Behaviour Research and Therapy, 87, 188-95. doi: 10.1016/j.brat.2016.09.012

Fata, L., Birashk, B., Atefvahid, M., K., \& Dabson, K., S. (2005). [Meaning assignment structures/ schema, emotional states and cognitive processing of emotional information: comparing two concep-tual frameworks (Persian)]. Iranian Journal of Psychiatry and Clinical Psychology, 11(3), 312-26.

Garland, E. L., Gaylord, S. A., \& Fredrickson, B. L. (2011). Positive reappraisal mediates the stress-reductive effects of mindfulness:
An upward spiral process. Mindfulness, 2(1), 59-67. doi: 10.1007/ s12671-011-0043-8.

Garland, E. L., Gaylord, S., \& Park, J. (2009). The role of mindfulness in positive reappraisal. EXPLORE: The Journal of Science and Healing, 5(1), 37-44. doi: 10.1016/j.explore.2008.10.001.

Garnefski, N., Kraaij, V., \& Spinhoven, P. (2001). Negative life events, cognitive emotion regulation and depression. Personality and Individual Differences, 30, 1311-27. doi: 10.1016/S01918869(00)00113-6.

Gefen, D., Straub, D., \& Boudreau, M. C. (2000). Structural equation modeling and regression: Guidelines for research practice. Communications of the Association for Information Systems, 4(1), 7.

Ghezelbash, S., Peyrovi, H., Inanloo, M., Haghani, H. (2015). [Relationship between Social Anxiety and Some Demographic Characteristics among Nursing Students (Persian)]. Journal of Health and Care, 17(1), 19-29.

Goldin, P. R., Ziv, M., Jazaieri, H., Werner, K., Kraemer, H., Heimberg, R. G., et al (2012). Cognitive reappraisal self-efficacy mediates the effects of individual cognitive-behavioral therapy for social anxiety disorder. Journal of Consulting and Clinical Psychology, 80(6), 1034-40. doi: 10.1037/a0028555.

Grant, B. F., Hasin, D. S., Blanco, C., Stinson, F. S., Chou, S. P., Goldstein, R. B., et al. (2005). The epidemiology of social anxiety disorder in the united states: Results from the national epidemiologic survey on alcohol and related conditions. Journal of Clinical Psychiatry, 66(11), 1351-61. doi: 10.4088/jcp.v66n1102

Hayes, S. C., Strosahl, K., Wilson, K. G., Bissett, R. T., Pistorello, J., Toarmino, D., et al. (2004). Measuring experiential avoidance: A preliminary test of a working model. The Psychological Record, 54(4), 553-78. doi: 10.1007/bf03395492

Hofmann, S. G., \& Bögels, S. M. (2006). Recent advances in the treatment of social phobia: Introduction to the special issue. Journal of Cognitive Psychotherapy, 20(1), 3-5. doi: 10.1891/jcop.20.1.3.

Kabat-Zinn, J. (1994). Wherever you go, there you are: Mindfulness meditation in everyday life. New York: Hyperion.

Kashdan, T. B., Farmer, A. S., Adams, L. M., Ferssizidis, P., McKnight, P. E., \& Nezlek, J. B. (2013). Distinguishing healthy adults from people with social anxiety disorder: Evidence for the value of experiential avoidance and positive emotions in everyday social interactions. Journal of Abnormal Psychology, 122(3), 645-55. doi: $110.1037 / \mathrm{a} 0032733$

Kingsbury, M., \& Coplan, R. J. (2016). RU mad@ me? Social anxiety and interpretation of ambiguous text messages. Computers in $\mathrm{Hu}$ man Behavior, 54, 368-379. doi: 10.1016/j.chb.2015.08.032

Kline, R. B. (2011). Principles and practice of structural equation modeling, ( ${ }^{\text {rd }}$ Ed.). New York: Guilford Press.

Kocovski, N. L., Fleming, J. E., \& Rector, N. A. (2009). Mindfulness and acceptance-based group therapy for social anxiety disorder: An open trial. Cognitive and Behavioral Practice, 16(3), 276-89. doi: 10.1016/j.cbpra.2008.12.004

Kocovski, N. L., Fleming, J. E., Hawley, L. L., Ho, M. H. R., \& Antony, M. M. (2015). Mindfulness and acceptance-based group therapy and traditional cognitive behavioral group therapy for social anxiety disorder: Mechanisms of change. Behaviour Research and Therapy, 70, 11-22. doi: 10.1016/j.brat.2015.04.005. 
Kocovski, N. L., Fleming, J. E., Hawley, L. L., Huta, V., \& Antony, M. M. (2013). Mindfulness and acceptance-based group therapy versus traditional cognitive behavioral group therapy for social anxiety disorder: A randomized controlled trial. Behaviour Research and Therapy, 51(12), 889-98. doi: 10.1016/j.brat.2013.10.007

MacKenzie, M. B., \& Kocovski, N. L. (2010). Self-reported acceptance of social anxiety symptoms: Development and validation of the Social Anxiety - Acceptance and Action Questionnaire. International Journal of Behavioral Consultation and Therapy, 6(3), 214-32. doi: 10.1037/h0100909

Modinos, G., Ormel, J., \& Aleman, A. (2010). Individual differences in dispositional mindfulness and brain activity involved in reappraisal of emotion. Social Cognitive and Affective Neuroscience, 5(4), 369-77. doi: 10.1093/scan/nsq006

Nolen-Hoeksema, S. (1991). Responses to depression and their effects on the duration of depressive episodes. Journal of Abnormal Psychology, 100(4), 569-82. doi: 10.1037/0021-843x.100.4.569

Nolen-Hoeksema, S., Wisco, B. E., \& Lyubomirsky, S. (2008). Rethinking rumination. Perspectives on Psychological Science, 3(5), 400-24. doi: 10.1111/j.1745-6924.2008.00088.x.

Ohayon, M. M., \& Schatzberg, A. F. (2010). Social phobia and depression: Prevalence and comorbidity. Journal of Psychosomatic Research, 68(3), 235-43. doi: 10.1016/j.jpsychores.2009.07.018.

Orzech, K. M., Shapiro, S. L., Brown, K. W., \& McKay, M. (2009). Intensive mindfulness training-related changes in cognitive and emotional experience. The Journal of Positive Psychology, 4(3), 21222. doi: 10.1080/17439760902819394.

Panayiotou, G., Karekla, M., \& Panayiotou, M. (2014). Direct and indirect predictors of social anxiety: The role of anxiety sensitivity, behavioral inhibition, experiential avoidance and self-consciousness. Comprehensive Psychiatry, 55(8), 1875-82. doi: 10.1016/j. comppsych.2014.08.045.

Petrocchi, N., \& Ottaviani, C. (2016). Mindfulness facets distinctively predict depressive symptoms after two years: The mediating role of rumination. Personality and Individual Differences, 93, 92-6. doi: 10.1016/j.paid.2015.08.017

Radomsky, A. S., Ashbaugh, A. R., Saxe, M. L., Ouimet, A. J., Golden, E. R., Lavoie, S. L., et al. (2006). Psychometric properties of the French and English versions of the Social Phobia Inventory. Canadian Journal of Behavioural Science / Revue Canadienne Des Sciences Du Comportement, 38(4), 354-60. doi: 10.1037/cjbs2006021

Sandoz, E. K., Wilson, K. G., Merwin, R. M., \& Kellum, K. K. (2013). Assessment of body image flexibility: the body image-acceptance and action questionnaire. Journal of Contextual Behavioral Science, 2(1), 39-48. doi: /10.1016/j.jcbs.2013.03.002

Shapiro, S. L., Carlson, L. E., Astin, J. A., \& Freedman, B. (2006). Mechanisms of mindfulness. Journal of Clinical Psychology, 62(3), 373-86. doi: 10.1002/jclp.20237.

Shikatani, B., Antony, M. M., Kuo, J. R., \& Cassin, S. E. (2014). The impact of cognitive restructuring and mindfulness strategies on postevent processing and affect in social anxiety disorder. Journal of Anxiety Disorders, 28(6), 570-9. doi: 10.1016/j. janxdis.2014.05.012.

Stopa, L., \& Clark, D. M. (2000). Social phobia and interpretation of social events. Behaviour Research and Therapy, 38(3), 273-83. doi: 10.1016/s0005-7967(99)00043-1
Storch, E. A., Roberti, J. W., \& Roth, D. A. (2004). Factor structure, concurrent validity, and internal consistency of the beck depression inventory-second edition in a sample of college students. Depression and Anxiety, 19(3), 187-9. doi: 10.1002/da.20002.

Taylor, S., Abramowitz, J. S., \& McKay, D. (2012). Non-adherence and non-response in the treatment of anxiety disorders. Journal of Anxiety Disorders, 26(5), 583-9. doi: 10.1016/j.janxdis.2012.02.010.

Trompetter, H. R., Bohlmeijer, E. T., Fox, J. P., \& Schreurs, K. M. (2015). Psychological flexibility and catastrophizing as associated change mechanisms during online Acceptance \& Commitment Therapy for chronic pain. Behaviour Research and Therapy, 74, 50-9. doi: 10.1016/j.brat.2015.09.001.

Vassilopoulos, S. P., \& Banerjee, R. (2008). Interpretations and judgments regarding positive and negative social scenarios in childhood social anxiety. Behaviour Research and Therapy, 46(7), 870-6. doi: 10.1016/j.brat.2008.03.008.

Weinrib, A. Z. (2011). Investigating experiential avoidance as a mechanism of action in a mindfulness intervention [ $\mathrm{PhD}$ thesis]. Iowa City: University of Iowa.

Werner, K. H., Goldin, P. R., Ball, T. M., Heimberg, R. G., \& Gross, J. J. (2011). Assessing emotion regulation in social anxiety disorder: The emotion regulation interview. Journal of Psychopathology and Behavioral Assessment, 33(3), 346-54. doi: 10.1007/s10862-0119225-x.

Zanjani, Z. (2010). comparison of body image among Three groups showing social phobia shyness and normal individuals. Journal of Psychology, 13(4), 391-406. 
